\title{
A scientific correlation between dystemprament in Unani medicine and diseases: a systematic review
}

\author{
Sepideh Miraj ${ }^{1}$, Sara Kiani ${ }^{2}$
}

\begin{abstract}
${ }^{1}$ M.D., Gynecologist, Fellowship of Infertility, Assistant Professor, Faculty of Medicine, Shahrekord University of Medical Sciences, Shahrekord, Iran

${ }^{2}$ Research Assistant, Cellular and Molecular Research Center, Shahrekord University of Medical Sciences, Shahrekord, Iran
\end{abstract}

\section{Type of article: Systematic review}

\begin{abstract}
Background: Temperament or mezaj refers to four different humors differentiating in individuals and, as a result, proposes specific therapy for their diseases.

Objective: The aim of this study was to overview the scientific correlation between temperaments in Unani medicine and diseases.

Methods: This study was carried out from March 2015 to February 2016. A computerized search of published articles was performed using PubMed, Google Scholar, Scopus and Web of Science, and Medline databases as well as local and regional resources between 1983 and 2014. The search terms used were temperament, dystemprament, diseases, mizaj, sue mizaj. Additional sources were identified through cross-referencing.

Results: The result of this study indicated the relationship between dystemprament and incidence of some diseases such as muscle diseases, skin diseases, asthma, palpitation, bipolar disorder, hemodialysis hysteria, hypertension, sinusitis, aging, diabetes, diarrhea. However, further studies are needed to prove the role of dystemprament in incidence of other diseases.

Conclusion: The result of this study indicated the relationship between dystemprament and incidence of some disease such as muscle diseases, skin diseases, asthma, palpitation, bipolar disorder, hemodialysis hysteria, hypertension, sinusitis, aging, diabetes, diarrhea. These results are helpful for patients and physicians to change humors toward equilibrium to avoid diseases. Further studies are required to discover the relationship between dystemprament and other diseases.
\end{abstract}

Keywords: Dystemprament, Unani medicine, Mizaj, Humor

\section{Introduction \\ 1.1. Background}

Unani medicine is based upon theory of humors, which presupposes the presence of four humors in the body: dam (blood), balgham (phlegm), safra (yellow bile), and sawda (black bile) $(1,2)$. The mizaj (temperaments) of individuals are revealed accordingly by the words sanguine, phlegmatic, choleric, and melancholic on the preponderance of the respective humor (3). In Unani medicine, the human body is contemplated to contain the following five components: temperament (mizaj), bodily temperament, humor, spirit, a'da, function (4). This Ruh is responsible for the contraction and relaxation of muscle fiber or muscular activity (5). Besides, there is a residual power of self-preservation or adjustment endowed by nature, called Tabi'at (medicatrixnaturael) (6). Hadmudwi consists of the chemical changes that facilitate sustenance of life and functioning of cells and for which certain nutrients and substrate are required to enter into and the wastes and synthesized product of the cells to come out of them. Protein synthesis under the influence of genes (DNA) can come under this function $(7,8)$. A condition where muscles of an organ or the whole body become flaccid is called istirkha and huzal, which may be caused by (9) nutritional deficiencies. Duchenne muscular dystrophy (DMD) signs and symptoms are related to the istirkha and

\section{Corresponding author:}

Sara Kiani, Cellular and Molecular Research Center, Shahrekord University of Medical Sciences, Shahrekord, Iran. Tel: +98.9140204896, Fax:+98.3222546, Email: kiani.sandra@yahoo.com

Received: April 30, 2016, Accepted: September 24, 2016, Published: November 2016

iThenticate screening: September 01, 2016, English editing: October 08, 2016, Quality control: November 02, 2016 (C) 2016 The Authors. This is an open access article under the terms of the Creative Commons Attribution-NonCommercialNoDerivs License, which permits use and distribution in any medium, provided the original work is properly cited, the use is non-commercial and no modifications or adaptations are made. 
huzal. DMD is the most common and severe form of muscular dystrophy seen in malea (9). Zakaria Razi (865-925 AD) critically assessed, in his book Al-Havi, (10), all the available knowledge on istirkha at that time. The use of medicinal herbs and herbal medicines is an age-old tradition, and the recent progress in modern therapeutics has stimulated the use of natural products worldwide for diverse ailments and diseases (11-25).

\subsection{Statement of problem}

As Unani therapy is dependent upon equilibrium, if there is any change in mizaj the equilibrium is disturbed in any way the life is threatened $(21,22)$. Each of these humors was associated with and was classified as having the following qualities: hot and moist, cold and moist, hot and dry, and cold and dry (21). Galen introduced for the first time the concept of temperament derived from the Latin word "temperate," which means to mix (23). The different temperaments are sanguineous, phlegmatic, melancholic, and bilious. It is said that each person possesses a dominant plus a subdominant temperament (21). Kant stated that knowing what sort of a person has a disease is more important than knowing what sort of disease a person suffered from (23). Among the temperaments, the sanguine and melancholic were emotional types, and the phlegmatic and bilious types were action types (24). In children the same temperament labels are referred to as aggressive, fearful, apathetic, and impulsive (25).

\subsection{Objective of research}

The aim of this study was to overview results of articles regarding the role of temperament disturbance in suffering diseases.

\section{Material and Methods}

\subsection{Design}

A computerized search of published articles was performed using PubMed, Google Scholar, Scopus and Web of Science, and Medline data bases as well as local and regional references. The search terms used were "temperament, dystemprement, mizaj, sues mizaj, diseases.” Additional sources were identified through cross-referencing.

\subsection{Inclusion and exclusion criteria}

The following keywords were used to a search for the relevant articles published from 1983 and 2014; their full text should be available in English. Articles included consisted of clinical trials, in vitro, in vivo, review, or metaanalysis studies. All relevant studies were evaluated on the basis of the titles and abstracts. Exclusion criteria were just abstracts and not available in the time line of the study. Those article that did not match our inclusion criteria (being in languages other than English during the time line of the study). Irrelevant studies as well as studies on prevention of disease and temperament from epidemiological perspectives were excluded from the study.

\subsection{Quality assessment}

The sampling method, existence of valid instruments and presence of inclusion and exclusion criteria were checked. The search results identified 25 articles; however, 16 studies were excluded from the review, leaving nine articles for further analysis.

\section{Results and discussion}

\subsection{Clinical disorder}

The results of this study indicated that a number and percentage of patients have the same dominant and subdominant temperament with a specific clinical disorder as identified.

\subsubsection{Muscle diseases}

Unani physicians describe different types of istirkha: rabw istirkha'i (shortness of breath due to the paresis of respiratory muscles); laqwa istirkha'i (deviation of face due to flaccidity of the facial muscles); istirkha' al-hanjara (flaccidity of laryngeal muscles due to the infiltration of fluids in them; in this condition the movement of larynx is stopped); istirkha' al-mi'da (condition where tonicity of the muscles of stomach is lost; it is due to retention of fluid in the stomach, severe vomiting, and diarrhea); istirkha' al-maq'ad (flaccidity of the anal canal due to paresis and paralysis of sphincter muscles, which leads to involuntary expulsion of stool and gas from the anus); istirkha' almathana (flaccidity/paresis of muscles attached to urinary bladder with or without injury of bladder followed by incontinence of urine); juhuz istirkha'i (protrusion of eyeball due to paresis of eye muscles and ligaments attached to it); istirkha' al-jafn (drooping of upper eyelids due to paralysis of eye muscles or congenitally due to the defect of the muscles of eye); istirkha' al-lisan (condition where the tongue becomes flaccid, there is increased salivation and patient feels difficulty in speaking); istirkha' al-litha (flaccidity of the gums in which they become spongy); istirkha' 
al-safan (flaccidity of scrotum); istirkha' al-qadib (flaccidity of the penis) (23). Etiology (Asbab): x-linked recessive disorder, obstruction occurs in asab (nerves), excess rutoobat in azlat $(26,27)$.

\subsubsection{Skin diseases}

According to Zakaria Razi, bahaq is a common dermal disease featured by hypopigmentation and hyperpigmentation (1). Akbar Arzani has classified bahaq into two types: (a) bahaq abyaz is a mild hypopigmentation that appears suddenly and disappear quickly after the topical use of detergent drugs $(4,5)$; (b) bahaq aswad is a black discoloration of skin featuring the appearance of wheat shell-scales $(5,29)$.

\subsubsection{Asthma}

Among 12 patients with asthma, 10 suffered from phlegmatic temperament of dominant/subdominant types $(25,30)$.

\subsubsection{Palpitation}

Palpitation was divided according to its causes in traditional medicine, for example, based on hot, cold, moist, dry, and the combination of these dystemprament (31).

\subsubsection{Bipolar disorder}

In this special issue dedicated to Falret and the French contributions to the concept of cyclicity in manic depressive illness, we begin with a historical overview of the development of the concept of cyclicity and its fundamental significance in manic-depressive illness, and we underscore how the concept fell into neglect only to reemerge in recent years. We then look at the intimate relationship between mania and depression. The hypothesis of the primacy of mania is discussed. The thesis is presented, supported by the examination of 100 consecutive index manias that, in most cases, mania is triggered by external factors acting upon hyperthymic patients, determining an exogenous cyclicity. On the other hand, in BPII patients the temperamental mood instability (cyclothymia) is an inherent and decisive factor in determining the cyclic autonomous course of the disorder. Finally, a new distinction of bipolar disorders, based on premorbid temperament and course of the illness, is considered (25).

\subsubsection{Hemodialysis}

In the correlation of the characteristics and the mental health of the different temperamental patients with hemodialysis, in order to provide a psychological base for psychological nursing care, it was concluded that there was positive correlation to compare the personalities of anxiety, fear, paranoia, and the mental diseases with the points of EPQ mental personalities. There were negative correlations between the points of each SCL-90 element, except elements of body and antagonism, and the points of cover-up personalities. The points of each SCL-90 elements in patients group with choleric temperament and depressive temperament were higher than those in the patients group with sanguine and mucous temperaments. Conclusions: patients with hemodialysis all have mental problems in different levels. The mental health of choleric and depressive temperamental group was worse than that of sanguine and phlegmatic temperamental groups. Thus we should pay attention to the influences caused by the characteristics of different temperaments on the diseases and aim mental nursing care to patients with different characteristics (32).

\subsubsection{Hysteria}

Hippocrates stated for the first time that disease is due to the imbalance of humors (33). Besides, mental disorders were traditionally assorted into three types: mania, melancholia, and hysteria (5). In the book Firdausul Hikmah by Rabban Tabbari, mental disorders were classified into 13 types, e.g., sa'ra, waswasah, hizyan, fasade khayal, fasadeaq'l, nisyan, bedaari, dawi, duwar, etc. (34). The same number of mental diseases was mentioned by Razi in his book Kitabul Fakhir (35). Hysteria is similar to epilepsy and unconsciousness. Its origin is in the uterus, but it involves the heart and brain. It is mentioned in Unani classical literature with clinical pictures and detailed treatments. Nomenclature: A. Because the patient feels as if an air ball arises from her abdomen or pelvis and obstructs the pharynx, it is called "bao-gola" in Hindi. B. Because the patient feels as if she has been throttled, in the past, the disease was associated with uterine disorders; therefore it has been named as "ikhtanak-ur-rehem." C. Hysteria is a Unani word derived from "hysteria," which means uterus. The pathogenesis of general diseases in Unani medicine has been ascribed to three factors, e.g., temperament, structure, and continuity of tissues. Abnormalities of these factors are called altered temperament, altered structure, and discontinuity in tissues, respectively $(8,9)$. ShaikhurRayees Abu Ali Hussain bin Abdullah bin Sina (980-1037 A.D) described that hysteria is similar to epilepsy and syncope. Its origin is in the uterus, but it involves the heart and brain. It occurs due to amenorrhea and retention of semen. It occurs in pre-pubertal girls, multigravida, and lactating mothers. Due to retention of semen, the temperament of women is diverted toward the boroodat (coldness). Due to baroodat (coldness) the viscosity of semen and menstrual blood increased; hence it remains in the uterus. When it remains in the uterus for a long duration, it becomes toxic (sammimadha), which lead to tashanuj and pressure in the vessels. Due to retention, the uterus gets diverted to one side. Sometimes toxic vapors reach up to the brain and hearing, which results in unconscious and syncope (26). Erudite written in his time, Abu Bakar bin Mohammed Zakaria Razi (865-925 A.D.) stated that once it came to my observation to see women who have aborted and has unconscious and 
the pulse was zaheef and sageer, and sometimes the pulse was not identified. Another incidence of my life was to see women who were conscious and not in synoptic condition, but the condition of breathlessness was present. Another incident was to see women who have epileptic conditions. All these conditions suggest that hysteria has many types. Sometimes the condition will occur in which it is difficult to identify if the woman is alive or dead. Razi stated that hysteria occurs due to amenorrhea and retention of semen. In most cases, it occurs due to retention of semen. It occurs in virgin females because their sexual desire is not fulfilled. If froth comes out after an attack, it is a good sign (27). According to Shareef Shafuddin Ismael Jurjani (died in 1140 A.D.) and Mohammed Kabeerud din (1894-1976 A.D.), hysteria is similar to epilepsy and syncope. Its origin is in the uterus, but it involves the heart and brain. Its causes are sometimes amenorrhea and accumulation of blood or it causes increase in secretions or its retention. It generally happens in unmarried females or in those patients who are habitual coitus. So when menses or secretions are blocked, it gets diverted toward coldness, which is very usual and sometimes its conversion occurs toward the putrefaction and hotness (hararat). Thus the toxicity is either cold (barid) or hot (haar), which appears in the uterus and also affects the heart and brain (36). There are two forms in which this toxic substance (sammimadha) can affect the brain and heart. First, the uterus is affected; it get displaced to one side; due to displacement, the heart and brain will be effected. Second, when toxic substance (sammimadha) becomes faasid in the uterus, then toxic vapours reaches the heart and brain and causes disease. If its toxic substance (sammimadha) goes toward the brain, it causes epilepsy, spasms, or paralysis. Hakim Mohammad Hassan Qarshi stated that disease is more common in young, sophisticated females, especially when the nervous system is congenitally deformed, or if they show inherited susceptibility to this disease. Along with this, complaints of amenorrhea, puerperium, leucorrhoea, and displacement of the uterus are common. According to pioneers of Unani medicine, occasionally this disease also arises as a result of retention and putrefaction of seminal fluid along with severe constipation, impaired digestion, flatulence, anger, stress, anxiety, fears, sorrows, etc., and some psychological factors that are exaggerated. Sudden shocks are the predisposing factors. Prolonged insomnia and excessive fatigue are also the underlying causes (37). Maseehul Mulk Hafiz Hakeem Ajmal Khan (1894-1976 A.D.) noted that the origin of hysteria is in the uterus and called it ikhtinaq-ur-rehm. He stated that it occurs in rich females of delicate temperament and in females between the ages of 12-40 years living in cities. Amenorrhea and dysmenorrhea can also cause this disease. He further stated that chronic constipation, nafakh-e-shikam, distress, sorrow, anxiety, fear, and anger can all causes the disease (31). "Ancient medicine have called this disease hysteria, derived from the name of the uterus, because it is an organ given to women by nature in order that they be able to become pregnant" (25). Improvement is ideally possible through restraining from sexual intercourse and frequent virginity. Patients with hysteria should be cured with care and caution. These diseases can be best prevented by hot baths, massages, and exercise (25, 32). Shareef Shafuddin Ismael Jurjani and Mohammed Kabeerud din mentioned the following clinical picture. It starts with paroxysms of morbid fascination (imagination), darkness before eyes, tinnitus, pain below umbilicus, loss of appetite, difficulty in respiration, palpitation, fatigue, weakness in legs, and change in color occurs. Eyes become watery and when the time comes closer than suffocation, palpitation starts. Uncontrolled movements occur in the mouth, lips, and face; the teeth start making noise; the voice gets choked. Breathing becomes feeble. Patient will feel as if something is going up from her pubis symphysis. She does not talk but understands whatever is said to her, then she becomes unconscious, and there is loss of sensation (28, 29). Abu Bakar bin Mohammed Zakaria Razi described the following clinical picture of hysteria. Respiration gets ceased; pulse become weak. Teeth start making noise. Uncontrolled movement overtakes half of the body (27). Maseehul Mulk Hafiz Hakeem Ajmal Khan mentioned the following sign and symptoms. The disease occurs with fits. Fits can occur for few minutes, a few hours, and, in some cases, it occurs for two to four days and mostly occurs during menstrual periods. First, the patient feels pain in the hip, watering of eyes, headache, patient become weak and lazy, darkness occurs in front of the eyes. After sometime a ball (gola) arises from the stomach of patient toward the throat and obstructs it, to which patient tries to swallow and asphyxia occurs. Rigidity occurs in the throat, belching, frequency of mictruation increases, the heart beat increases, and the patient starts shouting and cries or starts laughing loudly and becomes faint and fall on the ground. The spasm occurs in her limbs, respiration increases, and limbs become cold. Sometimes the patient pulls her hairs and sometimes tears her cloths. She hates the people around her and tries to bite them. She strikes her hand on the wall and takes her fingers toward the throat again and again, which indicates a sign of obstruction. When the disease starts to disappear, the patient gasps and shivers and starts and sometimes lies calmly. At last she smiles, and the fit ends and urination occurs in more quantity (21). Hakim Mohammad Hassan Qarshi mentioned the following clinical features, which commonly initiate from seizures. They vary according to their severity. Most commonly, the patient feels mild pain on the left side of the pelvis, after which the sense of an air ball arising from stomach and obstructing pharynx is felt, which compels the patient to make an attempt for its elimination for which she has recurrent deglutition. This causes asphyxia, resulting into syncope. In mild cases, the syncope is not serious; therefore the patient is able to recover soon. Although the patient succeeds in recovering, she suffers from 
unbearable fatigue, headache, nuchal rigidity, flatulence, impaired digestion, palpitation, etc. Urinary incontinence and depressive moods are also common. If the condition is severe, the patient has shrill cries or she laughs madly, and once the sensation of the air ball reaching the pharynx is felt, she soon falls on the ground. The patient beats her chest and bends her head backward along with extending the neck upward. Sometimes a spasmodic condition of lymph is also reported, and the patient tries to move her body forward or backward or even tends to fold herself. Stiffness is accompanied with this. In some cases, the patient is as stiff as a tie, or stiffening of one limb is also seen. Up and down movements are also evident. The patient beats her upper limbs here and there, blinks the eyes; there is ballooning of nostrils and compression of lower jaw without any ugly character of the face. A few patients also pull the hair, tear their clothes, bang on the wall, and try to chase the surrounding individuals (38). The patient takes long and deep breaths upon rubbing her neck frequently; there is coldness of both limbs. Therefore the duration of seizures ranges from a minutes to a few hours or two to three days. The reoccurrence of the seizures depend upon the intensity and severity of the disease. Once the seizures subside, the patient starts having breathlessness along with tremors on being touched and becomes anxious. The patient is calm and quite and laughs whole heartedly or cries loudly. The patient sleeps after vomiting. Many times, a few patients show fake symptoms in between the seizures, the senses are dumped. Sometimes the patient is often stubborn and irritable and gives a long explanation of her clinical features, which is in excess of reality. She assumes them to be very critical and pretends to have fake seizures and pain at different sites in the body. Mostly she complains of hemiplegic, although the condition is rare. The patient complains of incomplete symptoms such as an inability to walk, although she is capable to stand without any support and walk. Moreover, there is no urinary or stool passage involuntarily; there is no facial or lingual paralysis, only she walks (crawling). In such individuals, the left aspect of the body is paralyzed. The subject is hypersensitive, complains of hoarseness of voice - and nausea, hiccups, flatulence, palpitations, spasmodic cough are common (30).

\subsubsection{Hypertension}

In a study, the relationship between some diseases and the temperament of individuals was investigated; it was shown that 15 patients had a dominant/subdominant sanguineous temperament (39). In another open pilot study conducted by second-year medical students at the Nelson Mandela School of Medicine at the University of Natal, the association between temperament and Type II diabetes mellitus showed positive results. In this study involving 77 confirmed diabetics, the results indicated that $89 \%$ of the patients had a dominant or subdominant sanguineous temperament. Of course, this was not a fully standardized questionnaire, and the limited sample size is a limitation of this study (40).

\subsubsection{Sinusitis}

In the Unani system of medicine, it can be termed as iltehabtajaweefe anaf and can be haad (acute) or muzmin (chronic) according to duration of illness and haar (hot) and baarid (cold) according to the predominant humor (28). It is a major health care problem that affects a large population, mainly of the lower age group. In the wake of unconvincing scenarios of treatment coupled with obnoxious side effects in contemporary medicine, the Unani system of medicine offers an effective treatment for this disease based on its holistic approach. In this system of medicine, various regimes of regimental therapy are used for primary and secondary prevention of sinusitis along with evaluation of mizaj (temperament) of a person. Mizaj is one of the fundamental concepts of Unani medicine and serves as a primary tool for diagnostic and therapeutic purposes. Determination of mizaj is an important tool for prophylaxis of sinusitis. Screening is one of the procedures by which disease can be diagnosed in its early stage, and the possible steps can be adopted in time to reduce the morbidity and mortality, e.g., blood pressure for hypertension and pap smear for cancer of cervix are two example of how screening helps in combating the fatal outcomes of diseases. Keeping in view of the above potential of sinusitis, the present study entitled "Demographic Study of Sinusitis in Patients Visiting Govt. Unani Hospital Srina-gar and AYUSH Centres in Kashmir" has been designed. The objective of the study was to evaluate the prevalence rate of sinusitis and to determine the ratio of diseases in respect of mizaj of the patients attending Govt. Unani Hospital/AYUSH Centres in Kashmir, irrespective of the treatment the patient is seeking (41).

\subsubsection{Aging}

According to classical Unani literature, organismal ageing is the result of two opposing processes: 1) Tahleel-erutoobat by harat-e ghareezia to maintain organism in functional state; 2) inadequate compensation of tahleel by quwwatehazima, which maintains balance or homeostasis. This imbalance causes decrease in rutoobat-e ghareezia and hararat-e ghareezia thus changes the mizaj to barid yabis. Gradual increase in baroodat with age weakens the quwa and slows the affal of the body because quwa requires hararat for affal. Any quwwat is not immortal and decreases gradually with age. Tabiyat, the supreme power of the body is also a quwwat, which weakens with advancing age and alter all functions of the body. At the molecular level, it is accepted that the aging process is the result of entropy-driven decay, mutations and oxidative stress resulting in generalized impairment of functions, loss 
of adaptive response to stress, immunosenesence and increasing the risk of age related diseases such as decreased power, vision, memory, locomotion or immobility, exertional dyspnea, depression, gastrointestinal distress, changes in the skin, heart disease, cardiovascular diseases, respiratory diseases, and musculoskeletal diseases (42).

\subsubsection{Diabetes}

According to Unani medicine, ziabetus shakri is a disease in which consumed water is passed out through the kidney immediately after intake by the patient. It is similar to zalqul medawal ama (irritable bowel syndrome) in which the food passes rapidly through the stomach and intestine without proper digestion (43). In this disease, the patient feels excessive thirst and takes plenty of water and passes all the water he consumed without any metabolic change (44). The term "diabetes" was first coined by Araetus of Cappodocia (81-133 A.D.). Later, the word mellitus (honey sweet) was added by Thomas Willis (Britain) in 1675 after rediscovering the sweetness of urine and blood of patients (43). The Unani philosophy of disease causation is based on mizaji (temperamental) and saakhti (structural) deviation. Any imbalance between mizaj and saakht (structure) results in disease. In this disease, the mizaj (temperament) of kidneys becomes Haar (hot), so they absorb water from blood circulation and send to the urinary bladder immediately due to weakness in quwate masika (retentive power). It has also been described that kidneys attract the watery substance of blood, but the urinary bladder does not attract anything. Thus, the kidneys attract water from the circulation, liver, stomach, and intestines; because of this, the patients feel immoderate thirst (polydipsia) (43).

\subsubsection{Diarrhea}

Galen (131-201 A.D.) defined diabetes as "diarrhea urinosa" (diarrhea of urine) and "dipsakos" (thirsty disease). He described it as a disease specific to kidneys because of weakness in their retentive ability, and as he came across only two cases of diabetes, he termed it a rare disease. He believed that the urine of diabetic patients was an unchanged drink, which may have accounted for different aromas (45). The Chinese and Japanese literature explained a disease with sweet urine, which attracted dogs and insects. Such patients were more prone to develop boils and tuberculosis (38). During the fifth and sixth centuries, the sweet taste of urine in polyuric patients was also described in the Sanskrit (Indian) literature by Susruta, Charaka, and Vaghbata, and the disease was named "madhumeha." They described that the urine of these patients tasted like honey (madhu), wassticky to touch, and ants were strongly attracted to it (46).

\section{Conclusions}

The result of this study indicate the relationship between dystemprament and incidence of some diseases such as muscle diseases, skin diseases, asthma, palpitations, bipolar disorder, hemodialysis hysteria, hypertension, sinusitis, aging, diabetes, diarrhea. These results are helpful for both patients and physicians to change humors toward equilibrium to avoid diseases. Further studies are required to discover the relationship between dystemprement and other diseases.

\section{Acknowledgments:}

We appreciate the Research and Technology Deputy of Shahrekord University of Medical Sciences for its technical and financial support.

\section{Conflict of Interest:}

There is no conflict of interest to be declared.

\section{Authors' contributions:}

Both authors contributed to this project and article equally. Both authors read and approved the final manuscript.

\section{References:}

1) Islam N, Ishaq M, Bukhari B, Siddiqui MK. AI-Qanun: Ibn Sina's contribution to the world of medicene. J Cent Asian Stud. 2009; 18(1): 143.

2) Rahman A, Ali SJ, Zulkifle M, Ahmad I. Concept of Akhlat Arba (four humors) with relation to health and disease. Int J Herb Med. 2014; 2(4): 46-9.

3) Nagamia hf. Ibn al-Nafîs. JISHIM. 2003: 1.

4) Jazi R, Asli FO. (Avicenna’s Pharmacopoeia). Rev Hist Pharm (Paris). 1998; 45(317): 9-28. PMID: 11625300 .

5) Wollumbin J. Galenic medicine in the 21st century. J Aust Trad-Med Soc. 2013; 19(2): 89-94.

6) Moodley R, Sutherland P, Oulanova O. Traditional healing, the body and mind in psychotherapy. Couns Psychol Q. 2008; 21(2): 153-65. doi: 10.1080/09515070802066870. 
7) Bhuyan KC, Bhuyan DK. Regulation of hydrogen peroxide in eye humors effect of 3-amino-1H-1, 2, 4triazole on catalase and glutathione peroxidase of rabbit eye. Biochim Biophys Acta. 1977; 497(3): $641-51$. doi: 10.1016/0304-4165(77)90284-7. PMID: 889879.

8) Reddy DV, Kinsey VE. Composition of the vitreous humor in relation to that of plasma and aqueous humors. Arch ophthalmol. 1960; 63(4): 715-20. doi: 10.1001/archopht.1960.00950020717015. PMID: 14436800.

9) Duffy J. From humors to medical science: A history of American medicine: University of Illinois Press; 1993.

10) Longe JL, Blanchfield DS. The Gale encyclopedia of medicine. 2001.

11) Miraj S, Azizi N, Kiani S. A review of chemical components and pharmacological effects of Melissa officinalis L. Der Pharmacia Lettre. 2016; 8(6): 229-37.

12) Miraj S, Rafieian K, Kiani S. Melissa officinalis L: A Review Study With an Antioxidant Prospective. Journal of evidence-based complementary \& alternative medicine. 2016. doi: 10.1177/2156587216663433. PMid: 27620926

13) Sha'bani N, Miraj S, Rafieian-Kohpayei M, Namjoo AR. Survey of the detoxification effect of green tea extract on the reproductive system in rats exposed to lead acetate. Advanced biomedical research. 2015;4:155. doi: 10.4103/2277-9175.161582, PMid:26380240, PMCid: PMC4550946

14) Miraj S, Alesaeidi S. A systematic review study of therapeutic effects of Matricaria recuitta chamomile (chamomile). Electronic physician. 2016;8(9):3024-31. doi: 10.19082/3024, PMid: 27790360, PMCid: PMC5074766

15) Esteki R, Miraj S. The Abortificient Effects of Hydroalcoholic Extract of Lawsonia Inermis on BALB/c Mice. Electronic physician. 2016;8(6):2568-75. doi: 10.19082/2568, PMid: 27504174, PMCid: PMC4965209

16) Sepideh Miraj. Overview of Flaxseed Patent Applications for the prevention and treatment of human cancer. Der Pharma Chemica, 2016, 8(14):33-38 .

17) Miraj S, Kiani S. Study of pharmacological effect of Ocimum basilicum: A review. Der Pharmacia Lettre, 2016; 8(9): 276-80.

18) Miraj S, Kiani S. Astragalus membranaceus : A review study of its anti-carcinoma activities. Der Pharmacia Lettre. 2016; 8(6): 59-65.

19) Miraj S, Kiani S. Study of pharmacological effect of Avena sativa: A review. Der Pharmacia Lettre. 2016; 8(9): 137-40.

20) Miraj S, Kiani S. Study of pharmacological effect of Mentha pulegium: A review. Der Pharmacia Lettre. 2016; 8(9): 242-5.

21) Miraj S, Kiani S. Bioactivity of Sesamum indicum: A review study. Der Pharmacia Lettre. 2016; 8(6): 32834.

22) Miraj S, Kiani S. Study of therapeutic effects of Cynara scolymus L: A review. Der Pharmacia Lettre. 2016; 8(9): 168-73.

23) Masoudi M, Rafieian Kopaei M, Miraj S. A comparison of the efficacy of metronidazole vaginal gel and Myrtus (Myrtus communis) extract combination and metronidazole vaginal gel alone in the treatment of recurrent bacterial vaginosis. Avicenna J Phytomed. 2016; (6): 1-7.

24) Baghbahadorani FK, Miraj S. The impact of Silymarin on improvement of platelet abnormalities in patients with severe preeclampsia. Elect Phys. 2016; 8(5): 2436-42. doi: 10.19082/2436. PMID: 27382456, PMCID: PMC4930266.

25) Masoudi M, Miraj S, Rafieian-Kopaei M. Comparison of the Effects of Myrtus Communis L, Berberis Vulgaris and Metronidazole Vaginal Gel alone for the Treatment of Bacterial Vaginosis. J clin diag res. 2016; 10(3): QC04-7. doi: 10.7860/JCDR/2016/17211.7392． PMID: 27134945, PMCID: PMC4843330.

26) Bhika R, Haq HMA. Tibb traditional roots of medicine in modern routes to health. Mountain of Light SA. 2000; 168.

27) Mir SR. Text book of pharmacognosy, Alternate Systems of Medicine. C.B.S Publications, New Delhi 2nd Edition. 2014.

28) Kagan J, Snidman N, Arcus D, Reznick JS. Galen's prophecy: Temperament in human nature. Basic Books. 1994.

29) Husain A, Sofi G, Tajuddin DR, Kumar N. Unani system of medicine introduction and challenges. Med J Islam World Acad Sci. 2010; 18(1): 27-30.

30) Emde RN. Syndromes of Temperament: A Review of Galen's Prophecy. 1995. doi: 10.1037/004095. 
31) Pugh JF. Concepts of arthritis in India's medical traditions: Ayurvedic and Unani perspectives. Soc sci \& med. 2003; 56(2): 415-24. doi: 10.1016/S0277-9536(02)00049-7. PMID: 12473325.

32) Tanwir M, Ansari A, Aisha P, Anzar M. Dalk (Therapeutic Massage) \& Their Indication for Musculoskeletal Disorder in Unani Medicine. Int J Adv Ayurveda, Yoga, Unani, Siddha Homeopath. 2013; 2(1): 59-70.

33) Said HM. The Unani system of health and Medicare. J Tradition Res. 1983.

34) Routh HB, Bhowmik KR. Traditional Indian medicine in dermatology. Clin dermatol. 1999; 17(1): 41-7. doi: 10.1016/S0738-081X(98)00070-4. PMID: 10089584.

35) Akhtar J, Ansari A, Farhin N, Rasheed H. Incidence of Zeeq-un-Nafas Shoabi (Bronchial Asthma) in Individuals of Different Temperaments. J Homeop Ayurv Med. 2014; 3(147): 2167-06.

36) Ershadifar T, Minaiee B, Gharooni M, Isfahani MM, Nikbakht Nasrabadi A, Nazem E, et al. Heart palpitation from traditional and modern medicine perspectives. Iran Red Cres Med J. 2014; 16(2): e14301. doi: 10.5812/ircmj.14301. PMID: 24719741, PMCID: PMC3965874.

37) Gardner JK, Thomas-Hawkins C, Fogg L, Latham CE. The relationships between nurses' perceptions of the hemodialysis unit work environment and nurse turnover, patient satisfaction, and hospitalizations. Nephrol Nurs J. 2007; 34(3): 271-81. PMID: 17644871.

38) Javed G, Anwar M, Siddiqui M. Perception of psychiatric disorders in the Unani system of medicine-a review. Europ J Integ Med. 2009; 1(3): 149-54. doi: 10.1016/j.eujim.2009.09.004.

39) Bagadia VN, Shah LP, Pradhan PV, Gada MT. Treatment of mental disorders in India. Prog neuropsychopharmacol. 1979; 3(1-3): 109-18. doi: 10.1016/0364-7722(79)90075-4. PMID: 401334.

40) Yadav V, Jayalakshmi S, Singla RK. Traditional systems of medicine-Now \& Forever. 2012.

41) Naz S, Sherani F. Determination of human temperament based on the literature of Unani system of medicine. J Ayur Holi Med. 2014; 2(5): 38-43.

42) Āzamī AA. Basic Concepts of Unani Medicine: A Critical Study: Dept of History of Medicine, Faculty of Medicine, Jamia Hamdard. 1995.

43) Jabin F. A guiding tool in Unani Tibb for maintenance and preservation of health: a review study. Afr J Tradit Complement Altern Med. 2011; 8(5Suppl): 140-3. doi: 10.4314/ajtcam.v8i5S.7. PMID: 22754067, PMCID: PMC3252723.

44) Rahman SZ, Khan RA, Latif A. Importance of pharmacovigilance in Unani system of medicine. India $j$ pharmacol. 2008; 40(Suppl 1): S17-20. PMID: 21369407, PMCID: PMC3038517.

45) Nahas R, Moher M. Complementary and alternative medicine for the treatment of type 2 diabetes. Can Fam Physician. 2009; 55(6): 591-6. PMID: 19509199, PMCID: PMC2694078.

46) Sher H, Alyemeni MN. Ethnobotanical and pharmaceutical evaluation of Capparis spinosa L, validity of local folk and Unani system of medicine. J Med Plants Res. 2010; 4(17): 1751-6.

47) Itrat M, Haque N. concept of aging in unani medicine. Int J Res Ayu Pharm. 2013; 4(3).

48) Nazamuddin M, Wadud A, Ansari AH, Alam T, Perveen A, Iqbal N. Concept of Diabetes in Unani System of Medicine: An Overview. Med J Islam World Acad Sci. 2014; 22(3): 117-22. doi: 10.12816/0008182.

49) TIB M. Clinical Study of Ziabetus Shakari (Diabetes Mellitus Type II) and Evaluation of Efficacy of a Unani Formulation in its Management: Rajiv Gandhi Uni Health Sci. 2012.

50) Sina I. Al-Qanoon Fil-Tibb (English Trans. p. 251). New Delhi: Jamia Hamdard. 1993.

51) Sheehan HE, Hussain S. Unani Tibb: History, theory, and contemporary practice in South Asia. ann America Acad Polit Soc Sci. 2002; 583(1): 122-35. doi: 10.1177/0002716202583001008. 